\title{
Some Observations on the Morphological Index in Lepromatous Leprosy
}

\author{
S. G. B R OW N E, O.B.E., M.D., F.R.G.P., F.R.G.S., D.T.M. \\ Leprosy Service Research Unit, Uzuakoli, Eastern Nigeria
}

The Morphological Index (M.I.) may be defined as the average of the percentages of morphologically normal forms ('solid rods') of Myco. leprae found in smears taken from a given number of sites by a standard procedure and stained and examined by a standard technique. It thus indicates the proportion of bacilli that are presumably viable and capable of multiplying. There is the same need for uniformity in obtaining and expressing the M.I. as there is for the Bacterial Index (B.I.) if results from one centre and another, from different patients at the same centre, and from the same patient on different occasions are to be comparable. Technique, and the criteria for dividing the stained bacilli into 'solid rods' and 'other forms', are standardized. These 'other forms' comprise coccoid and irregularly stained organisms, acid-fast debris having the general outline of bacilli, and acidfast dust no longer recognizably bacillary in form. This second morphologically heterogeneous group thus includes all varieties of degenerate and effete bacilli, presumably non-viable and incapable of multiplying.

The M.I. probably furnishes the most direct and delicate indication available of the efficacy of a bactericidal or bacteriostatic drug; it is an index of a comparatively simple therapeutic effect, uncomplicated by such factors as removal of non-viable mycobacteria and immunological response to antigenic acid-fast material.

Two aspects of drug therapy needing emphasis concern the wide range of variation existing between one untreated patient and another in the proportion of bacilli morphologically normal, and the variation of this proportion in the natural history of the untreated disease. While it is not nowadays ethically justifiable to deny treatment to an individual patient, it so happens that opportunities occur from time to time to observe these changes.
Failure to recognize these variations may vitiate the results deduced from therapeutic trials. Their importance underlines the difficulty of 'pairing' in double-blind trials by adding an important but unpredictable variable to the number of primary considerations already to be appraised - age, sex, form of leprosy, its severity and duration, the B.I., etc. The inherent difficulties of observation and interpretation of the results of a prolonged therapeutic trial in which both bacterial morphology and tissue reactivity are assessed, are thus aggravated by the virtual impossibility of beginning the trial in the same circumstances with an adequate number of comparable individuals.

The present paper summarises an analysis of the M.I. findings in I 54 patients with lepromatous leprosy recently under observation in the Research Unit, Uzuakoli.

\section{Technique}

Material from eight sites (two each from the edge of a lesion, from the ear-lobes, from apparently normal skin, and from the nasal mucosa) is taken every fortnight for two months, and then at monthly intervals until individual bacilli are no longer recognizable.

The percentage of normal forms is estimated from examination of 200 bacilli from typical fields, excluding globi, since it is impossible to determine the form of the individual bacilli present in globi.

\section{Initial height of the morphological index}

Every care was taken to ascertain that these patients had never taken anti-leprosy drugs obtained clandestinely. The serum of several patients selected at random was examined by the Bratten and Marshall technique for the presence of sulphones, and found to be negative. 
The B.I. was calculated on the Dharmendra notation, in which the range is zero to 4 . $\mathrm{O}$.

The initial height of the M.I. in the untreated patient with lepromatous leprosy, completely Mitsuda negative, was found to vary within the widest possible limits. In nine patients, over 94 per cent of bacilli were classified as morphologically normal, whereas in five, fewer than io per cent could be called normal. In two of the first group, all the bacilli were normal, and in one of the latter, none were normal.

The range and scatter are summarized in:

TABLE I

\begin{tabular}{|c|c|c|c|c|c|c|c|}
\hline \multirow{2}{*}{$\begin{array}{l}\text { Number } \\
\text { of } \\
\text { patients }\end{array}$} & \multirow{2}{*}{$\begin{array}{l}\text { B.I. } \\
\text { range }\end{array}$} & \multirow[b]{2}{*}{ Average } & \multicolumn{4}{|c|}{ M.I. } & \multirow{2}{*}{$\begin{array}{l}\text { Average per cent } \\
\text { morpholo- } \\
\text { gically } \\
\text { normal forms }\end{array}$} \\
\hline & & & $\begin{array}{l}75 \text { - гоo } \\
\text { per cent }\end{array}$ & $\begin{array}{l}50-74 \\
\text { per cent }\end{array}$ & $\begin{array}{l}25-49 \\
\text { per cent }\end{array}$ & $\begin{array}{l}\mathrm{O}-24 \\
\text { per cent }\end{array}$ & \\
\hline 88 & $3 \cdot 0-4 \cdot 0$ & $3 \cdot 39$ & 26 & 39 & I 4 & 9 & $5 \mathrm{I}$ \\
\hline 53 & $2.0-2.9$ & 2.50 & I 2 & 19 & I 6 & 6 & $4^{I}$ \\
\hline 13 & I . O-I .9 & I . 66 & 5 & 1 & 2 & 5 & $4^{I}$ \\
\hline
\end{tabular}

Just as the B.I. is the average of the Index from all the sites smeared, the M.I. similarly takes no cognizance of variations between the sites, since for the general purposes for which the indexes are employed, such distinctions are not important. It is, however, worthy of note that the M.I. may show considerable differences between the different sites smeared; in particular, smears from the nasal mucosa often reveal a much higher index than those from skin and ear-lobes, the higher index may persist for longer in the nasal mucosa, and normal bacilli may reappear in the nasal mucosa but not elsewhere.

The initial height of the M.I. is not related directly to the height of the B.I. The number of normal Myco. leprae appearing, and subsequently sampled by the slit-scrape technique, is a factor of the slow generation time of the bacillus. In the natural state, the number degenerating and losing their viability depends partly on a built-in survival time and partly on inimical factors in the micro-environment. The proportion of 'solid rods' and 'other forms' is the result not only of the combined effects of these factors, but also of the speed of removal from the tissues of non-viable and, possibly, also of viable bacilli. The absolute and relative importance of these various factors is still obscure and demands further investigation.

In general, and confirming clinical observations, the density of Myco. leprae and of globi per unit volume of tissue, as shown by the ordinary techniques of examination, increases with the duration of progressive lepromatous disease, but the height of the M.I. bears no direct relation to the actual volume of the granuloma that is sampled by smearing.

\section{The rate of decrease in the Morphological Index}

The speed at which the proportion of 'solid rods' progressively declines in the smears taken from the different sites in skin and nasal mucosa is commonly taken as the best evidence available for the efficacy of the drug under investigation. The component due to the action of the drug in the rate of decrease in the M.I. may, however, be supplemented both by the above-mentioned suspected factors causing variation in the height of the M.I., and by possible strain differences of Myco. leprae (as in Myco. tuberculosis).

It was found that in lepromatous leprosy with no borderline features the rate of fall in the M.I. bore no relation to its initial height. Patients with a low M.I. (of io to 30 , for instance) might continue to harbour normal bacilli for twelve months or more, whereas those with a M.I. of 85 or over might cease to have normal bacilli in their smears within three months of the beginning of treatment.

As far as possible, by clinical assessment, and by the lepromin test, care was taken to exclude from this series any patient presenting borderline features, which are known to be associated with rapid fall in the $\mathrm{M}$.I.

There was, however, some relation between the rate of fall of the M.I. and the initial height of the B.I., as shown in:

\section{Leprosy Review}


T $\triangle \mathrm{BL} \mathrm{E}$ I I

\begin{tabular}{|c|c|c|c|c|c|c|}
\hline \multirow{3}{*}{$\begin{array}{l}B . I . \\
\text { range } \\
\\
3.0-4 \cdot 0\end{array}$} & \multirow{3}{*}{$\begin{array}{l}\text { No. of } \\
\text { patients } \\
88\end{array}$} & \multicolumn{4}{|c|}{$\begin{array}{l}\text { Persistence (in months) } \\
\text { of normal bacilli } \\
\text { in smears }\end{array}$} & \multirow{2}{*}{$\begin{array}{c}\text { Average } \\
\text { (months) }\end{array}$} \\
\hline & & o-5 & $6-$ Io & I I- & over 20 & \\
\hline & & I 6 & 35 & 28 & 9 & I I $\cdot 3$ \\
\hline $2.0-2 \cdot 9$ & 53 & I 5 & 29 & 5 & 4 & $8 . \mathrm{I}$ \\
\hline I $. O-I \cdot 9$ & I 3 & 5 & $\mathbf{I}$ & 2 & 5 & 5.8 \\
\hline
\end{tabular}

It is evident that the fall in M.I. in patients under treatment will depend on the properties of the drug, the total bacterial population, and the accessibility of this population to effective concentrations of the drug. The known efficacy of widely-spaced small oral doses of dapsone is probably explicable on the basis of the long generation time of Myco. leprae. The actual level of sulphone present in the serum at a given moment bears no necessary relation to any essential aspect of therapeutic activity. The extreme infrequency of true resistance to dapsone would support this supposition.

The rate of decrease in the Mor phological Index and its relation to the disappearance of all acid-fast debris

It was found that there was no relation between either the initial height of the M.I. or its rate of fall, and the time taken for the clearance of all acid-fast debris from the sites smeared. Granted that a considerable concentration of normal bacilli must be present for a few to be seen in an ordinary microscopic smear preparation, it is nevertheless probable that repeated careful smearing which reveals consistent reduction in the loads of acid-fast debris would reveal now and again 'solid rods' if they were present in appreciable numbers.

It is customary to continue anti-leprosy treatment in patients with lepromatous leprosy for at least two years after the disappearance of acidfast material from all the smears. This course, and its corollary 'treatment for life at half the therapeutic dose', may in the present state of knowledge be advisable in view of the possible persistence of viable $M y c o$. leprae between nerve fibres and in deep organs, but it may be an unnecessary counsel of perfection in the majority of patients.

Variation in the rate of fall of the Morphological

Index in relation to the drug administered

In view of the considerations detailed above, it is not expected in such small series that there would be any clear-cut difference in the rate of fall of the M.I. depending on which of the recognized effective drugs were taken. The scatter was not greatly different as between dapsone (in standard or in small doses) and thiambutosine. B663 showed a definite slight superiority.

It was observed that whatever the drug given, a small proportion of patients (about one in eight) appeared to respond very slowly as judged by the rate of fall of the M.I. In about threequarters of patients with lepromatous leprosy in this series, 'solid rods' disappeared well within fifteen months; in the remaining quarter, they persisted for longer, in some cases for much longer. This observation, if confirmed in larger series, might suggest the possibility of a genetically determined difference in inactivating the drugs used, like the INAH-inactivation shown in some patients under treatment for tuberculosis (Mitchison, I 965).

\section{S U M M A R Y}

The Morphological Index (which is an expression of the average proportion of 'solid rods' found in multiple smears), has a considerable range in the untreated patient with lepromatous leprosy.

The M.I. bears no relation to the height of the Bacterial Index, nor necessarily to the rate of fall of that Index in the individual patient, nor to the time taken for all acid-fast material to disappear from the skin and nasal mucosa.

A small number of patients appeared to respond slowly, as judged by the rate of fall of the M.I., to standard therapeutic regimes.

A CKNOWLEDGEMENTS

My thanks are due to Dr S. O. Egwuatu, Chief Medical Officer, Ministry of Health, Eastern Nigeria, for permission to publish this article.

R E F E R E N CE

mitchison, D. A. (1965). Brit. med. F., r, i 333 . 